\title{
UNA CARNICERÍA REGENTADA POR MORISCOS EN EL ARRABAL DE SAN JUAN, DE ELCHE
}

Por

ROSA MARIA BLASCO

No cabe cuestionar hoy que los moriscos estaban a caballo entre dos culturas, y que con frecuencia seleccionaban los aspectos más positivos de una y otra para hacerlos suyos $\{1$; i en consecuencia, sólo podremos comprender a este grupo social desde el conocimiento profundo de la civilización islámica y de la occidental.

Una escritura notarial de obligación, suscrita en marzo de 1597 por el notario Vicente Esteve, recoge el arrendamiento de las "carnicerías del Raval de San Juan" de Elche, a unos cristianos nuevos vecinos de Crevillente y del mencionado barrio de San Juan. El análisis de este documento pone de manifiesto que la referencia a lo islámico y a lo occidental resulta necesaria, que los moriscos actúan y se comportan como gentes que pertenecen a esos dos mundos.

Según Lapeyre, el grupo morisco de Elche supone casi la tercera parte de toda la población (2), y conforma una comunidad que la escritura notarial llama "universitat del Raval de San Joan de la vila d'Elig". El término "universitat" supone que los moriscos formaban no sólo un grupo social con caracteres propios, sino que tenían también unas autoridades - ujurats y sindich» - específicas y distintas de las de los cristianos viejos. Es decir, había un doble municipio: uno para cristianos viejos y otros para moriscos, aunque tuvieran reuniones conjuntas para tratar cuestiones comunes y, por supuesto, ambos eran coordinados por el "general procurador y batlle del present marquesat d'Elig", cargo que en esta fecha recaía en Llois Tárrega.

Hasta aquí el documento nada aporta que desconociéramos.

Tampoco es novedad comprobar que los moriscos acudían ante notario para escriturar los tratos y acuerdos que realizaban. Esta costumbre, que comenzé poco después de la conquista cristiana, se generalizó pronto; por ello los protocolos notariales constituyen una fuente fundamental para conocer la realidad mudéjar y morisca. Pero las dificultades anejas a la documentación no-

(1) MAISO, J., y BLASCO, R. M., "Aproximación al grado de aculturación de algunas comunidades moriscas en la fecha de la expulsionn en Actes du Symposium International du CIEM sur Religion. Identité et Sources Documentaires sur les Moriscues Andolous, 1. II, Túnez, 1984, pp. 79.80.

(2) LAPEYRE, H., Gégraphie de /'Espagne morisque, París, 1959, p. 91 
tarial - dispersión, carencia de unos inventarios sistemáticos; dificultad paleográfica que presenta la escritura, junto con la necesidad de invertir muchas horas de trabajo hasta llegar a una explotación completa de los protocolos-, han hecho que su utilización hasta ahora, para estos temas, resulte totalmente insuficiente. Cuando todas las fuentes notariales se incorporen a la investigación, sin duda tendremos una visión más matizada y real del grupo morisco, y de esa etapa de la historia española que comienza cuando el Islam pierde su poder político.

Algo que he comprobado repetidamente es que la mujer morisca también va ante notario y participa en la escrituración documental exactamente igual que la mujer cristiana vieja. En el documento que dov a conocer se arriendan las carnicerías a tres matrimonios moriscos, y las respectivas esposas no quedan marginadas en un anonimato, sino que se mencionan sus nombres - Elionor Calla, Angela Maymona y Maria Tindal- y asisten al acto notarial. Concentrándome más en el tema del documento, es bien conocida la tesis de que en los lugares donde conviven cristianos viejos y cristianos nuevos las carnicerías de estas comunidades se encuentran separadas, independientes, y cada una es atendida por un cortador distinto. En la "Historia de la rebelión y castigo de los moriscos del Reino de Granadan. Mármol menciona ya esta realidad, y afirma que en los pueblos existía un cortador de carne cristiano y otro moro (3).

En la misma línea insiste Caro Baroja: "La tercera prohibición era la de comer carnes sin sangrar, sangre o animales ahogados, mordidos por otros o muertos en accidente, de suerte que la sangre quedara coagulada. Consideraban inmundas estas carnes, y las llamaban "halgharaham" (carnes malditas). Sus carnicerias estaban, pues, separadas y con matarifes especiales a cargo de lo que en ellas ocurría" (4).

Siempre que pueden, los moriscos atienden sus propias carnicerías para mejor cumplir los preceptos que en este punto les manda su religión. Pero a veces esto resulta imposible. Las autoridades, que tienden a eliminar toda huella de identidad morisca, imponen con frecuencia un carnicero cristiano viejo. En Tórtoles, localidad próxima a Tarazona, sucede asi; sabemos que alli «son todos moriscos excepto la casa del dicho vicario y del carnicero y el ama que está para recivir las criaturas" (5).

En cambio, en el arrabal de San Juan de Elche la situación es distinta: jurados y síndico, moriscos, arriendan la carnicería a cristianos nuevos.

La lectura del documento, redactado en un estilo mixto típico de las escrituras notariales, donde conviven lo formulario y el lenguaje espontáneo del pueblo, es muy ilustrativa y no tiene desperdicio.

Subrayo algunos aspectos.

Los animales que se van a sacrificar en estas carnicerías son el carnero - "moltón-y en menor proporción la oveja, que resulta el $70 \%$ más barata en el precio de venta. Excepcionalmente se pondrá a la venta carne de vaca para celebrar la fiesta de San Juan. No resulta extraña la falta de referencias al cer-

(3) Libro IV, capitulo $X X I 1$. BAE, XXI.

(4) CARO BAROJA, J., Los moriscos del Reino de Granada, Madrid, 1976. p. 132

15) Archivo Diacesano de Tarazona, cajón 9. , ligarza 3, número 8. 
do, pero en cambio llama la atención que no se mencione la cabra o el macho cabrío, típicos animales mediterráneos; tal vez su consumo y gran aprecio por la élite cristiana determinaba unos precios prohibitivos para los moriscos.

Para el sacrificio de los animales se destinan unos dias concretos: jueves y sábados; uno y otro son la vispera de la fiesta semanal islámica y cristiana.

De cara a un consumo especial de alimentación sólo hay una fiesta destacada a lo largo del año: el día de San Juan, fecha en que se unen la celebración cristiana del patrón, con el festejo del comienzo del verano, festejo que ha tenido siempre gran resonancia en el mundo mediterráneo.

En el pormenor con que se detalla el contenido de los capítulos radica el principal interés de esta escritura. Su texto puede servir de comparación para tratar de matizar hasta qué punto hay coincidencia o no cuando el arrendamiento de las carnicerias recae en cristianos viejos. En este sentido, echo en falta la publicación de textos relativos a monopolios municipales. También la parcela de la documentación municipal ha sido hasta ahora muy marginada, $v$ es urgente que la investigación se ocupe de esos fondos considerados "menores", pero que sin duda pueden iluminar y revelar nuevos aspectos de la vida en el pasado.

Joan Soot de Calla y Elionor Calla, cónyuges, nous christians vehins de la villa de Crevillent, Joan Aquem fill de Franciscus y Angela Maymona, cónyuges, Juan Maymó, rajoler, y Maria Tindal, cónyuges, etiam nous christians, vehins del Raval de Sant Joan de la vila de Elig, omnes simul et quilibet illorum per se et insolidum, gratis etc. cum presenti etc. prometen y se obliguen a Diego Sarria y Pere Banquexa, jurats de la dita Universitat del Raval de Sant Joan, y a Frances Benjuar, sindichs presents, en nom y com a representants de tota la dita universitat e singuiars persones de aquella aceptantes, e lo notari infrascrit a major fermetat pro absentibus estipulant y rebent etc. de provehir e complidament bastir e avituallar de carn la carniceria de la dita universitat del Raval de Sant Joan de moltó y ovella, per temps de un any comptador del dia de Pasqua de Resurrectió primer vinent en avant, a for e preu de vint y set diners la lliura de moltó, y la lliura de la ovella a denou diners, y guardar puntualment los capitols que per a dit arrendament son estats ordenats per dits jurats y sindich, los quals per lo infrascrit notari en presentia dels testimonis desus scrits los foren llets e donats a entendre de verbo ad verbum desde la primera linea fins la darrera inclusive, del modo y forma seguent.

Capitols abs los quals los jurats y sindich de la Universitat del Raval del Señor Sant Joan de la vila de Elig fan lo avituallament de les carns de la carniçeria del dit Raval, los quals han ordenat de provisio de Llois Tárrega, cavaller, general procurador y batle del present marquesat de Elig etc. $y$ de lliçençia de aquell hui qu'es conten lo primer del mes de marc, any de la nativitat del nostre Señor Deu Jesus Christ mil cinchcents noranta y set.

Primerament que lo asegurador y avituallador de dites carns y carniseria del dit Raval tinguen obligatio de donar fermanses bones y segures, a content dels dits jurats y sindich dins dos dies apres del remat, en altra manera dexant les de donar se puxa arrendar dit avituallament de nou y los menyscaptes $y$ danys qu'es causaran sien a carrech del primer arrendador que les tal fermanses no havra donat. 
Item que lo dit arrendador $y$ avituallador no puxen pendre mes de un partioner en sa compañia per evitar los inconvinients que se han seguit de ser molts los avitualladors, y que dins dos dies tinga obligatió de declarar als dits jurats lo partioner, $y$ dexant ho de fer que reste per entregue dit arrendament per aquell, y que en tot lo any no puxa acollir parsioner sino a voluntat dels dits jurats $y$ sindich.

Item que lo dit asegurador y avituallador ha de bastir dita carniseria de carn de moltó y ovella, ço es de pasqua fins tot agost ha de matar dos parts de moltó crestat y lo terç de la ovella, y de agost enllá tot moltó crestat com desus se declarará; y que dita carn ha de ser bona y rebedora a content dels dits jurats y sindich.

Item que lo dit avituallador tinga obligatio cascun dia de disapte, entre tres y quatre ores de la vesprada, matar totes aquelles reses que serán menester, y que en lo temps de regar y batir la hagen de matar un dia pera altre sots pena de sexanta sous aplicadors lo terç als dits jurats y sindich, y lo altre terç al fisch, y lo restant altre terç al acusador, y si acusador no y haurá ygualment sia partida entre aquells.

Item que lo dit asegurador tinga obligatio lo dia de Sant Joan matar dos vaques y vendre la carn de aquelles sens osos segons [borrado] preu qu'es vendia fa ovella, y si no les matara que en dit dia haja de vendre solament moltó al preu de la ovella.

Item si lo dit asegurador no bastirá complidament dita carniçeria de carn, com es dit, per cascun dia, encorrega en pena de sexanta sous partidors ut supra, y que los dits jurats y sindich, a despeses del dit avituallador, puxen comprar moltons $y$ ovelles y ferlos matar $y$ vendre en dita carniçeria, y provehir aquella complidament, $y$ tot lo qu'es perdra sia a carrech del dit avituallador; $y$ si enviaran alguna persona a provehirse de carn tinga obligatio lo asegurador de propich pagar lo gasto y costa que fará dit home.

Item que los dits jurats y sindich hajen de repartir los caps, peus, frexures y demés menucies de totes les reses que en dita carniçeria se mataran, sens que lo dit avituallador ni altra persona tinga que fer en la venda y repatiment de dites menusies.

Item que lo carniçer tinga obligatio de tenir les reses mortes y la carn de aquelles en los ganchos de la carniçeria a vista de la gent, y alli mateix haja de tenir lo grex y fetxe, y que no puxa tenir en altra part sots pena de deu sous aplicadors als dits jurats e sindich.

Item que lo dit carniçer, sots dita pena, haja de tenir la carn de moltó y ovella de per si de tal manera que en la taula on vendrá la carn de moltó no puxa estar la de ovella.

Item que lo dit carniçer los dies de dijous tinga obligatio de tallar y vendre carn, co es de dematí fins les deu, y de vesprada fins les tres ores, sots pena de deu sous aplicadors ut supra.

Item ninguna persona sia osada vendre carn fora de dita carniçeria, sots pena de sexanta sous y perdre la dita carn y preu de aquella, aplicadors ut supra. 
Item que lo asegurador tinga obligatio de nomenar tallador $y$ carnicer, bo e suficient, fiel y legal; en altra manera, dexant ho de fer, que dits jurats lo nomenen sens réplica ni contradictio, y que no puxe usar de remey algú de tal nominatio.

Item que nos puxa pesar ni tallar en dita carnisería carn mortesina, sino que la porten viva al matador, venint ella per sos peus aon lo carniçer la matará, e açó en pena de vint sous per cascuna vegada ques contravendrá de bens del asegurador, e aplicadors ut supra.

Item donem facultat al dits aseguradors e asegurador que puguen portar per los mijans de la orta lo ganado que desus li sera taçat, ab tal que no entren en plantats et panificats, e si faran dany en dits mijans esmenen aquells sens encorrer en pena.

Item que los dits aseguradors puguen entrar en dits mijans cinchcentes caps de ganado de moltons y ovelles pera obs de dita seguritat, y si mes ne portaran encorreguen en pena de deu lliures de moneda del present regne per cascuna vegada que seran trobats contravenir a dit capitol.

Itern si finit lo temps de dita seguretat los sobrara moltons y ovelles dels que havra pasturat en los mijans de dita orta, no puguen traure aquells ni vendrels si lo nou avituallador y los jurats los voldran, y en lo dit cas si en lo preu nos porran concordar, que to vell asegurador nomene un expert, y lo nou e o los jurats nomenen altre, y aquelis arbitren y estimen lo tal ganado, y si concordar nos porran que lo general procurador y batle nomene terçer.

Item no puguen llevar per cascun cap de moltó o ovella ab lo servell huit diners, y dos peus a diner, y per la frexura six diners, y per lo ventre dos diners.

E axi llests los dits obligats, vist lo contés en dits capitols, prometen observar y complir les coses en aquelles conteses y passar per elles prout facent, y no contravenir modo aliquo. Per lo qual axi attendre e complir obliguen ses persones e bens y renunçien a la esdepartida actio nova e vella constitutions, y la epístola del emperador Adriá y al fur de Valencia de principali prius conveniendo etc. Et les dites dones juraren etc. Certificades etc. Renunciaren etc. Et omni alii etc. E tots renunçien a oferta de bens sehents etc. Fiat etc. En lo present marquesat etc. Fiat large etc. Actum Elig ut supra.

Testimonis foren presents a la ferma dels dits Joan Soot, Joan Aquem fill de Frances y Angela Maymona, cónyuges, y de Joan Maymo, rajoler, Pere Flori y Francisco Xarqui, etiam nous cristians, vehins de dita universitat del Raval de Sant Joan, y quant a la ferma de les dites Leonor Calla, muller del dit Joan Soot, y Maria Tindal, muller del dit Joan Maymo, rajoler.

VICENTE ESTEVE.

Protocolo del año 1597. Sin foliar. 